\title{
The Analysis of the Comical Factors of 'Olaf' the Snowman in Frozen - Based on the Laughter Theory of Henri Bergson
}

\author{
${ }^{1}$ Eunkoung Lee, ${ }^{1}$ Myoungsik Choi and ${ }^{2,}$ a Kim Cheeyong \\ ${ }^{1}$ Dept. of Industrial Design KoungHee University \\ ${ }^{2}$ Dept. of Visual Information Engineering Dong-eui University \\ ${ }^{1}$ Ma-p-ya@nate.com, ${ }^{2}$ choims2020@hanmail.net, ${ }^{a}$ kimchee@deu.ac.kr
}

\begin{abstract}
From various media, animation is one of the media where the laughter effect can be the greatest. There are many reasons for the good production of the animation "Frozen" but I have focused mainly on the "laughter effect". Laughter is a main technique in communication and a persuasive way to give interest to the information. There are many theories by theorists on laughter and humor but on the basis of 'Le Rire' by Henri Louis Bergson, the Frozen had been applied to the laughter theory and one of the characters who had given a lot of laughter, the snowman, Olaf had been analyzed for its comical elements. Bergson had stated that there is no comical aspect if it is outside the boundaries of being humane, no emotional aspects should accompany laughter and that comedy should appeal for common sense. Olaf, the snowman, had been created through magic in the film and with the humane expressions and exaggerated movements it was shown to be more human-like and the situation of non-reality of being created by magic has left us in a spectator state, where it was accepted as common sense. Additionally, it was a character of good will which met the socially reasonable requests. Bergson had also categorized the types of laughter by shape, movement, situation, word/speech and personality, therefore laughter effect of 'Olaf' can be analyzed in these 5 types of laughter. The laughter effect of 'Olaf' had been analyzed on the types of laughter theory from many years back and has confirmed that even a newly created character had conformed in the types for character personality and design.
\end{abstract}

Keywords: Laughter, Comic, Humor, Character, Design, Animation, Henri Bergson

\section{Introduction}

The trend to find fun things which gives pleasure has been growing amongst many people in the modern society as they are stressed from hard and tedious work. The preference of news, politics and social issues are less on TV and newspapers as to humor, sports, entertainment which are showing an increasing trend [1]. This shows that humor is pursued more in many industries including the cultural industry.

Aristotle stated that people laugh at one's misfortune (superiority theory) and have defined that comedy is morally superficial. Kant stated that laughter comes from inconsistency (dissonance theory) [2]. Neuroscientist Ramachandran has stated that the origin of smiling had been the Pleistocene man grinning at a stranger to intimidate when encountered and then relaxing the expression when knowing that he is not a threat [3].

There are many theoretical definitions of laughter but it is hard to define in a general theory and as it is also subjective, therefore quantitative analysis is difficult. In the field of Psychology, much research has been done through a long period of time on the laughter of human, but platform on the creation and design of characters which deliver the laughter and 
humor is very tenuous and the sensitivity and sensibility of an artist in character design had been relied upon.

Animation had been a long popular item in United States of American and Europe as 'Gag' existed from the start and had been part of the media industry to give laughter to the audience. Most of the feature animations were produced by combining the genre of comedy and adventure to create a combined animation of comic, action and adventure [4]. Not only children enjoyed the animation but it has become an entertainment media for adults. Through this cultural flow, techniques and story lines have become more advanced and resulted in further research into the character creation and design. With the analysis to incorporate the comical character creation and design into many different media, this research is expected to be the theoretical base. On the basis of Bergson's views and types of laughter, the cause of laughter by the character 'Olaf' had been analyzed. In addition to understanding the cause of laughter the characteristics of laughter will need to be understood and theoretically analyzed so that it can be effectively incorporated into character creation and design of comical characters.

\section{Laugher Theory of Henri Bergson [5-6]}

\subsection{View of Laughter}

Firstly, there is no comical aspect if it is outside the boundaries of being humane. Being elegant, noble, worthless or even being hideous can exist but it is never a humorous thing. A view can be beautiful or ugly but it can never be humorous. People laugh or smile at an animal because we have recognized a humane behavior or an expression. We laugh at objects or animals because we have been able to find the similarities of human characteristics on them.

Secondly, there should not be emotional aspects accompanied in laughter. Laughter can only have the shaking effect when it is dropped on a mental surface of calm and order. Indifference is the best environment to experience laughter. There is no greater rival than emotion to laughter. People who have the mind that is sensitive to the surrounding, sympathize with life's ensemble and resonate emotionally to all incidents will not know or understand laughter. Let us try to stand back and look at one's life as a spectator. Most of the drama will become comical. If we cover our ears to the music in a party, this will be sufficient to make the dancers look foolish. When we forget our emotions and look at a thing in a rational way, we are able to laugh.

Thirdly, comedy appeals for common sense. Reaction to laughter is required. Our laughter is always a group laughter. You would have heard the life stories of a tourist in a train or in a restaurant, the people are for certainly laughing because the story is humorous and if you were part of it, you will be laughing too. People think that laughter is genuine but laughter hides the motive that it is sort of an agreement between a person and another (from reality or imaginary place). The more people in a theatre, the more the laughter will spread. Generally, comical effect cannot be translated from one language to another and it has been emphasized several times that it is related to one society's convention and ideas. It is certain that laughter has a social meaning as laughter is confronting certain requests of the social life.

By examining the three collected observation of laughter, it can be said that laughter is created when the sensitivity is suppressed and the body is only operated by intellect and all the attention is focused on one person. 
Table 1. View of Laughter

\begin{tabular}{c|l}
\hline \multicolumn{2}{c}{ View of laughter } \\
\hline Humanlike & $\begin{array}{l}\text { No comical aspect outside the boundaries of being } \\
\text { humane } \\
\text { Nublic indifference }\end{array}$ \\
Common sense & Comedy appeals for common sense \\
\hline
\end{tabular}

\subsection{Types of Laughter}

2.2.1. Laughter by Shape/Form: In aspects to actions, even though a face may be fine, the balance cannot be perfect. A cartoonist's skill is to catch small details of movement and to exaggerate it so that it can be seen in anyone's eyes as if to draw the expression when the model grins to the extreme. This would exist as an underlying human nature, crushed by a higher force, the imbalance or ugliness becomes a reality due to not being able to lift the head. Of course it is an exaggeration art but it is not just to express the exaggeration as a purpose. This is because there are caricatures which are more similar to the real person than a portrait, there are animations where the evidence of exaggeration cannot be seen and even with the vast exaggerations there are animations which could not show the true effects. For an exaggeration to be humorous, it should not be shown as a purpose but as a simple way for the artist to use to show us clearly the twists in the platform of the original nature. Instead of continuously renewing one's self by making contact with a living person, it tries to carve an attitude in a person who is absorbed and sucked into the mechanically operating corporeality. If an object makes the life of the mind dull externally and at the same time solidifies the act, by succeeding in contradicting the elegance, the comical effect will be obtained from the body. Therefore if we justify comicality by comparison to its opposite, it should be opposed to elegance rather than beauty. Being comical is more 'rigid' than to being 'ugly.

2.2.2. Laughter by Movement: Human's attitude, gesture and movement will induce direct proportional laughter when we associate the movement to a machine. If you want to verify this rule, you can do it by analyzing closely to a cartoonist's work. In proportional to the perspicuity and carefulness of showing the puppet in a person, in general the picture will become comical. The hint has to be clear as we have to be able to acknowledge the substitutable puppet inside the person like a transparent matter. Also the carefulness has to be present. Even though the arms and legs are stiff like parts of a machine overall impression should be that it is a living matter. When the shape and form of human and machine come together well, the comical effect is greater and the cartoonist's art becomes perfect. Additionally, the cartoonist's creativity becomes a special type of life put into an ordinary puppet. The act of imitating something can only be done when one person decides to give up being oneself. In other words our gestures which are only mechanical and uniform, will be able to imitate the distant part of our living personality. To imitate someone is to allow someone into one's body and draw out the mechanical aspects. Therefore imitating is defined as comical and will cause laughter. To change a living thing into mechanical aspects, it truly causes laughter. For a person to instantly change to an object, this will cause laughter. That is if a person and an object look alike, in all cases it will evoke laughter. 
2.2.3. Laughter by Situation: Henri Bergson explained the characteristics of the situation laughter by giving the examples of Jack in the box, Dancing Jack and Snow ball.

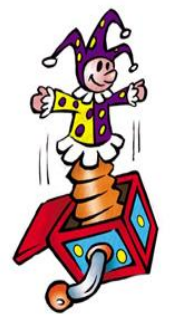

Figure 1. Jack in the Box

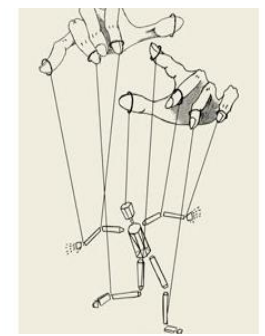

Figure 2. Dancing Jack

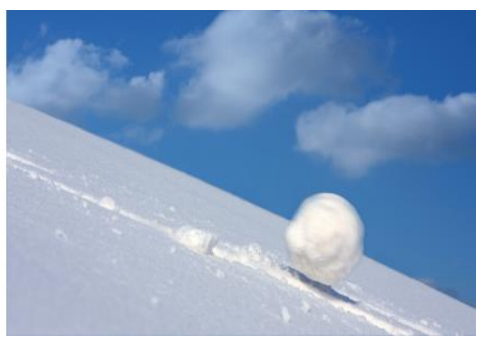

Figure 3. Snow Ball

Firstly, Jack in the box is a tug of war between two sides and eventually one side loses to another and this is where the humor is. This is a mental spring concept, where one person expresses a thought and the other person represses the idea but then a new idea is given and it keeps on going

Secondly, Dancing Jack makes us believe that a person is able to talk and act freely, but it is controlled by a being making it look free externally but in fact it is being controlled.

The importance of life comes from our freedom. Our matured feelings, incubated passions and decisions made through considerations are those that has come out from us and become our possession are those that will sometimes give dramatic or normal somber aspect to life. So to make all this comical, what do we need? To imagine that the shown freedom is controlled by hidden strings will be enough to make it comical.

Thirdly, a snowball becomes bigger as it rolls. Let us imagine waxed soldiers standing in one line. By touching the first one in line, it will fall on top of the second one in line and cause it to fall and it will fall on the third and so on causing a domino effect until all has fallen on the floor. For example, when a person touches a card on a house of cards and it wobbles and the card next to it might shake and begin to collapse. With acceleration, the collapse is fast and the end is reached in a short time. With the amplification and the expansion, an unexpected conclusion is created and reached from scratch. Additionally if there is a guest entering a room in hurry and he bumps into a lady who spills her tea on an old gentleman. The old gentleman slips on the floor and hits on the windows which fall down on a policeman's head at the bottom of the street. The policeman orders the full force out and so on. In these illustrations by comic artists there are objects which change location and people related to these objects. In these cases from one scene to another, the object's change of location will mechanically accompany the important changes between people to people. The characteristics of mechanically setup actions are that in general the opposite action can occur. A child enjoys the scene where he throws a ball at nine toy cylinders and sees them all fall down. But if the ball was to roll here and there and then stop and come back to the starting point, he will laugh more loudly. But why do we laugh at these mechanical structures? In the flow of life with humans and objects, we have a special understanding with rigid machines which we sometimes find as an intruder. Comedy is an aspect where a person resembles an object and a special type of rigidness where humane aspect imitates the lifeless action of machines and natural phenomenon. Therefore representing an incomplete individual or group which requires urgent correction. Laughter is said to be the correction itself. Additionally it a social action in pointing out and stopping the special absentness between human and an incident. 
Table 2. Types of Laughter

\begin{tabular}{c|l}
\hline \multicolumn{2}{c}{ Types of laughter } \\
\hline Laughter by shape/form & $\begin{array}{l}\text { Comedy is more 'rigid' than being 'ugly' } \\
\text { No emotional aspects should accompany laughter } \\
\text { Laughter by movement } \\
\text { Laughter by situation } \\
\text { Repetition of Jack in the box, Repetition of Dancing Jack, Reciprocal } \\
\text { Interference of Snow ball } \\
\text { Repetition, reversal and crossing, expressed in words is the concept of } \\
\text { laughter by word } \\
\text { Laughter by personality }\end{array}$ \\
\hline
\end{tabular}

2.2.4. Laughter by Word/Speech: Laughter cannot be caused mainly on the repetition of words. The repetition of words will only make us laugh when the mental element is represented by a special pleasure and itself represents a material pleasure. To categorize a joke into a specific category has an artificial meaning to it as the research till now on humorous effect had been created with the help of words. Laughter by word is reflected upon by the laughter by situation and movement and is fused with the laughter by personality. If the discussed types of laughter, such as the exaggerated form, mechanical movement, unexpected situation, repetition, reversal and crossing, are expressed as words, then that is the concept of laughter by word.

There has to be a distinction between a joke expressed in a language and joke created by a language. The former if needed can be translated to another language but the meaning can be mostly lost if taken to a society where the culture and literature is different especially when the ideas behind it is different. On the other hand, the latter is hard to translate to another language as the comedy is formed from the phrase's structure or the choice of words. Of course a phrase is not made by themselves, if we listen to it and laugh, we might as well laugh at the person who has said these words. However the last condition is not essential. This is because a phrase or a word has its own power of comedy. Furthermore the target of the laughter is not always the person who is presenting the joke. It is important to distinguish between spirituel and comique. If a phrase induces laughter about that person, then it is comique, and if laughter is induced by a third person or us, then it can be seen as spirituel. However most of the time it is hard to distinguish between being comique or spirituel. Firstly let us differentiate the broad meaning and short meaning of spirituel, in a language perspective of having a broad meaning people call the theatrical attitude as spirituel. People with spirituel are people who enjoy theatre very much. To an outstanding reader they have the talent to become an actor and a person with spirituel some will have the talent of being a poet. To have two idea systems crossing in the same word and phrase is one of the sources of having an amusing effect. In playing of words, it seems to have 2 separate meanings but in fact it is the same words and phrases. But it does not stop there in having a simple appearance. In fact there are two different phrases and words from a different language, and people act as if they are confused of the two phrases and words which sound similar to the ears. What we can use is the diverseness of the meaning of language. The comedy of word/speech is at the background of the comedy of situation and together they are immersed into the comedy of personality. Language is manmade object and it is a way of precisely imitating the different forms of the human mind, therefore it has the effect of evoking laughter. In our language it possesses our life and we feel things living. 
2.2.5. Laughter by Personality: If a person's personality could not impress our mind, that is when humor can start. A person who does not notice others and go on his own way is comical. Laughter always gives a certain amount of humility to the person who is the subject. A person who is ignorant will always be a target of a joke. We can accept that in general it is a person's flaw which gives us laughter. The flaw is seen as small not because it is small but because it gives laughter. The flaw can be seen to be comical not because of immorality but because of anti-sociality. We do not only laugh at other people's flaws but also at their merits. For us to be prepared to laugh the comedy uses the following general steps. It focuses our attention to the gesture rather than the act itself. Here, the gesture does not have any purpose nor gains but only point to the attitude, behavior and word expressed by the mental state affected by the action of the internal craving. If we define it this way, gesture and movement are different in nature. Movement is conscious and planned but gesture is casual and automatic. When we move away from the action and become a gesture, that is when we enter the territory of comedy.

Comical character is one of a type. In another words, if a thing shows even a mere similarity to a type, it contains the essence of comique. When acquainted with a person for a long time, there are times when nothing humorous can be found from a person but by coincidence if we attach a famously known name from a book or a movie onto a person, then that person will become a comical person to our eyes. Even though that character was not comical in the original story. Simply being similar to that character and driven by one self's ego, it would be comical as he would try to become part of the story that had been made for him.

\section{The Analysis of the Comical Factors of 'Olaf' the Snowman Based on the Laughter Theory of Henri Bergson}

\subsection{Laughter by Shape/form}

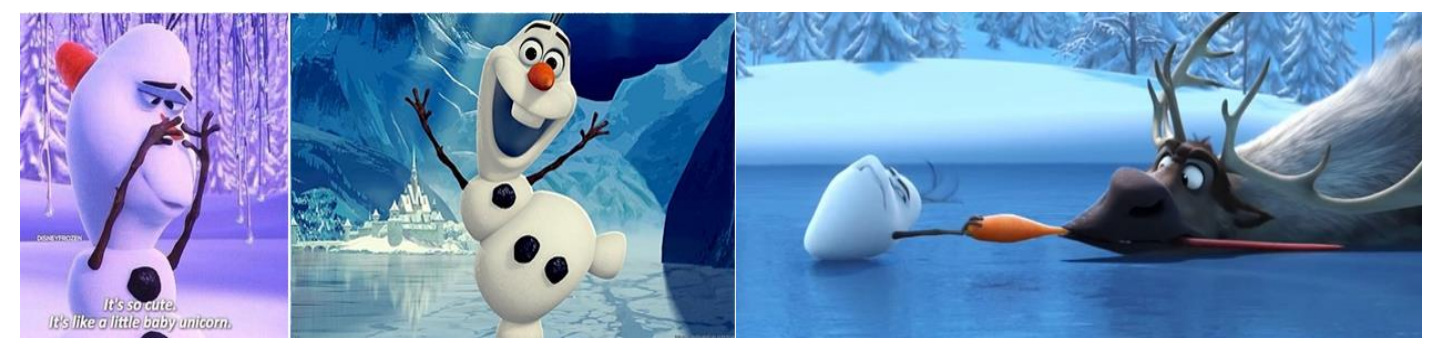

Figure 4. Shapes of Olaf

Bergson stated that when the contradiction to elegance succeeds, we obtain the humor effect from the body. Therefore if we justify comicality by comparison to its opposite, it should be opposed to elegance rather than beauty and by distorting the elegance by exaggeration will obtain the humor effect from the body as shape or form.

Olaf's shape does not have balance but also has a carrot nose. This increases the humor effect by shape/form as stated by Bergson about the exaggeration factors and Kant's dissonance theory. The carrot shape nose that Anna had given reminds us of a strawberry nose which make it more comical factor in the shape. By Olaf showing satisfied and enjoying expressions when he freely moves his carrot nose in and out, this brought more amusement to the audience. With the thick and long eyebrows sitting on top of the non-existing forehead, it looks like a hair split in the middle. In contrast to the narrow forehead the eyes are very big 
which can express emotions well and in contrast to the small chest, the abdominal area had been created big to achieve the stability but also reminds us of a potbelly. Additionally there are only two teeth in the protruded mouth which covers half of the face and having the shorts legs compared to the body, its design and a movement reminds us of a child or a penguin and brings out the laughter in us.

\subsection{Laughter by Movement}
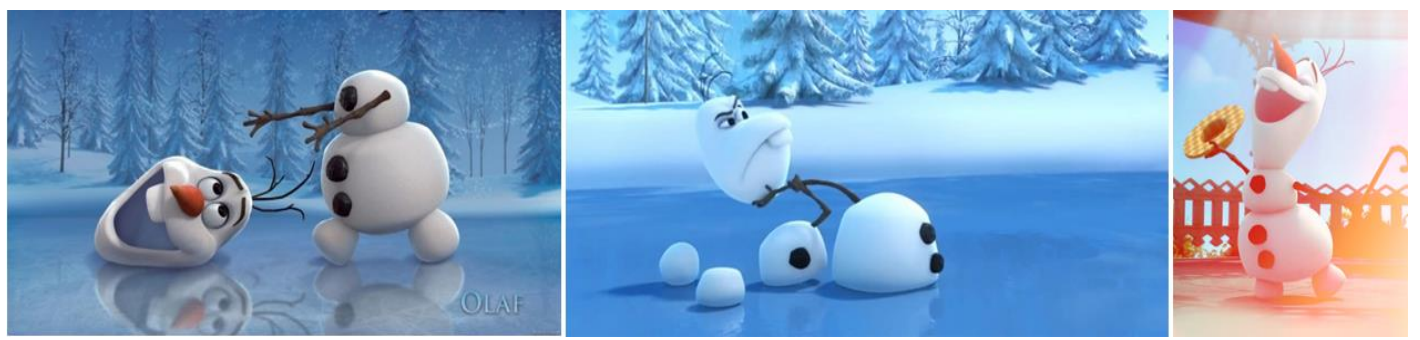

Figure 5. Movements of Olaf

Bergson stated that the cause of laughter is when a person suddenly changes into an object. When a person seems to be like an object, it will always evoke laughter.

Snowman is a character which represents winter but in a scene Olaf imagines himself enjoying summer and parodies a scene from 'The Umbrella of Cherbourg' by putting on a gentleman's hat and tap dancing with a cane. Warm summer day, tap dancing with his short legs and the animation parodying classic movies and contradicting weather selection had combined situations to give laughter. His movements had also been exaggerated as other characters in many animations, but with his short legs compared to his body, his movements remind of the walking movements of 'Charlie Chaplin'. When his body comes apart, his body, legs and head goes in all separate directions and when returning to one, his head is attached upside down and walks in a ludicrous way. Additionally when he wants to see far away he separates his head and lifts it up high in the hair with his hands and this represents Bergson's 'mechanical movement' which is a source of laughter.

\subsection{Laughter by Situation}

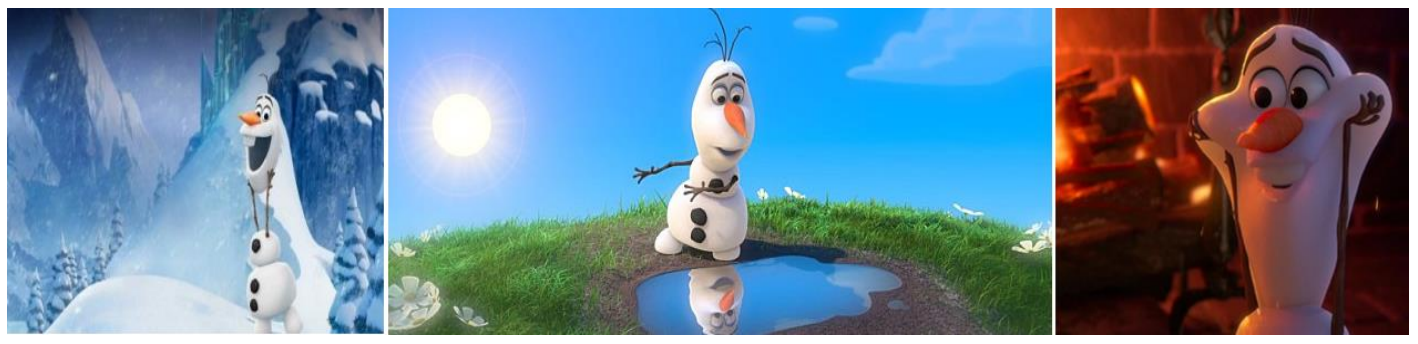

Figure 6. Situations of Olaf

Bergson has stated that comedy is an aspect where a person resembles an object and a special type of rigidness where humane aspect imitates the lifeless action of machines and natural phenomenon. 
Jack in the box: Different from normally exaggerated character, the body frequently separates and gives concerns to the audience but by combining into one again it gives assurance and laughter in repetition and reversal.

Dancing Jack: The scene where Olaf melts to the heat of a fireplace or the warm summer weather reflects that even though he seems to be free the situation itself is not free from the warm weather and heat from the fireplace. This also confines 'Dancing Jack'. A special type of life is put into an ordinary puppet to make comical expressions.

Snow ball: When escaping the palace with 'Anna' they roll on the snow literally being a 'snow ball' by intentionally, or as planned, it will never be known but as they keep on rolling on the snow, we question what would happen and eventually with the body separating and combining they do escape dramatically.

\subsection{Laughter by Word/Speech}

Bergson stated that exaggerated form, mechanical movement, unexpected situation, repetition, reversal and crossing, are expressed as words, then that is the concept of laughter by word. The repetition of words will only make us laugh when the mental element is represented by a special pleasure and itself represents a material pleasure.

After 'Anna' had made a nose out of the carrot intended for the reindeer, he was very satisfied and would ask if he was perfect. By ironically emphasizing the imbalanced shape, it induces laughter. When he first meets the reindeer, Olaf tells him that he looks weird and this evokes laughter as he is paradoxically expressing his imbalanced form. In the scene where the main character 'Anna' repeatedly asks about the whereabouts of 'Elsa' to Olaf, he repeatedly answers with "Yes, Why?" and this is an example of 'Jack in the box' where laughter is induced by repetition.

\subsection{Laughter by Personality}

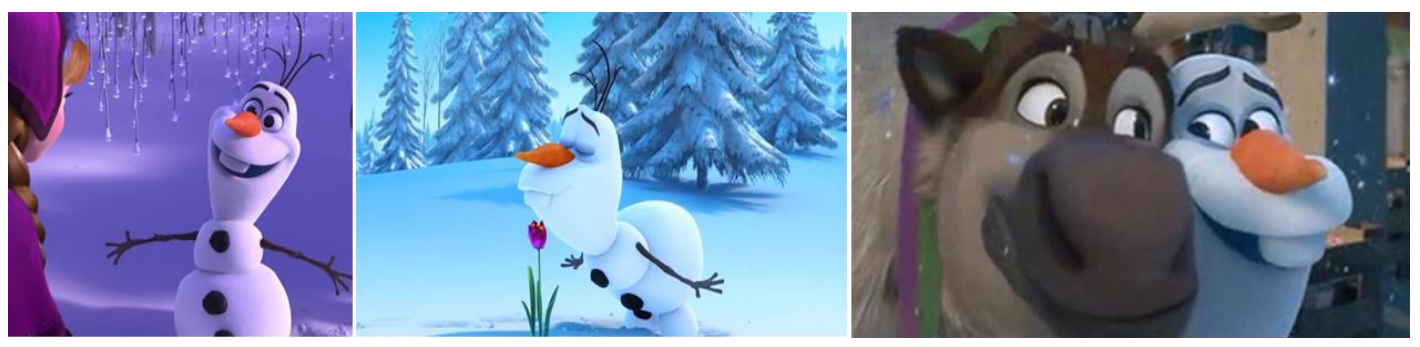

Figure 7. Personalities of Olaf

Bergson stated that other person's small flaw induces our laughter. The flaw is seen as small not because it is small but because it gives laughter. The flaw can be seen to be comical not because of immorality but because of anti-sociality. As he is melting in front of the fireplace he explains to 'Anna' about love and tries to get her to understand her sister 'Elsa' and this shows warm heartedness and friendliness of Olaf to the audience. In a scene Olaf mentions that "I do not have a skull so I do not get migraines" and this shows its optimistic personality where it uses its flaws to an advantage to increase the humor.

The carrot was intended to be the big reindeer Sven's food but he had allowed Olaf to use it as a nose and they had become friends. Through this the flaw of not having a nose had been supplemented and friendship arose sharing with us a more warm happiness. Additionally even with his head upside down he would greet people which showed his kind personality and by always giving a hug after greetings he showed friendliness. His determination and promises 
were easily given but he easily gave up and when he fought the 'marshmallow' giant he easily lost. With these personalities he had bluffed many times that he had helped 'Anna' and ensured that he will help her to escape. These were able to give the audience laughter as stated by Bergson that it was not due to immorality but due to the antisocial aspects of him. Therefore the small flaws and humiliations had been a source in giving laughter.

\section{Character Design}

Olaf is well known to be the first character to be created and designed in Frozen. There are not many scenes but this explains the importance of Olaf in this animation.

If we look at Olaf who represents well the elements of "exaggeration" by Bergson, we can notice he is a calculated design for a $3 \mathrm{D}$ character whose movements do not have limitations. The body frequently separates and does not restrict the movement and allows him to have big movements. The body had been designed to be thick but his arms were thin and long like a branch compared to the body. This is how people in the world would make a snowman but by having knots at the elbow area of the branch, the bending of his arms has been represented naturally. This also allowed the 3D character to have no restrictions in its arm movements. The big eyes and mouth helped to express emotions and even though he did not have a tongue, the audience did not notice and allowed the constructor to design and work easily with the character. As the mouth took up half of the face, it was easily used in exaggerations and with a big smile and two teeth in front, it allowed to hide the non-existence of the tongue but also show that it is not an empty mouth. Having thin branches on the head as hair is a way how people decorate a snowman and the shapes gives us warmth and feel sympathy. Children like and enjoy animations because it gives pleasure, satisfaction, and psychological satisfaction such as relaxation of tension8. The impossible settings and characters where their appearances or expressions are different from reality are expressed in a semi abstract image and deviated from everyday rules; portrayal of movements, non-reality exaggerations, nonlogical and absurd expressions which is only available in animations and the development of the story, satisfies the basic desires of children [7].

\section{Conclusion}

Table 3. Types of Laughter of Olaf based on the Theory of Bergson on the Types of Laughter

\begin{tabular}{|c|l|l|}
\hline Shape/form & $\begin{array}{l}\text { By succeeding in contradicting } \\
\text { the elegance, the comical effect } \\
\text { will be obtained. }\end{array}$ & $\begin{array}{l}\text { Imbalanced body with a carrot nose. } \\
\text { Narrow forehead with eyebrows } \\
\text { looking like hair split in the middle } \\
\text { and protruded mouth with only 2 } \\
\text { teeth. }\end{array}$ \\
\hline Movement & $\begin{array}{l}\text { Induce direct proportional } \\
\text { laughter when we associate a a } \\
\text { movement to a machine. }\end{array}$ & $\begin{array}{l}\text { When his body comes apart, his } \\
\text { body, legs and head goes in all } \\
\text { separate directions and when } \\
\text { returning to one, his head is attached } \\
\text { upside down and walks in a } \\
\text { ludicrous way. } \\
\text { For him to see far away he separates }\end{array}$ \\
\hline
\end{tabular}




\begin{tabular}{|c|c|c|}
\hline & & $\begin{array}{l}\text { his head and lifts it up high in the } \\
\text { hair with his hands. }\end{array}$ \\
\hline \multirow{3}{*}{ Situation } & $\begin{array}{l}\text { Jack in the box is a tug of war } \\
\text { between two sides and } \\
\text { eventually one side loses to } \\
\text { another and this is where the } \\
\text { humor is. }\end{array}$ & $\begin{array}{l}\text { The body frequently separates and } \\
\text { gives concerns to the audience but by } \\
\text { combining into one again it gives } \\
\text { assurance and laughter in repetition } \\
\text { and reversal. }\end{array}$ \\
\hline & $\begin{array}{l}\text { Dancing Jack makes us believe } \\
\text { that a person is able to talk and } \\
\text { act freely, but it is controlled by } \\
\text { a being making it look free } \\
\text { externally but in fact it is being } \\
\text { controlled. }\end{array}$ & $\begin{array}{l}\text { The scene where Olaf melts to the } \\
\text { heat of a fireplace or the warm } \\
\text { summer weather reflects that even } \\
\text { though he seems to be free the } \\
\text { situation itself is not free from the } \\
\text { warm weather and heat from the } \\
\text { fireplace. }\end{array}$ \\
\hline & $\begin{array}{l}\text { Reciprocal Interference of Snow } \\
\text { ball. } \\
\text { The amplification and the } \\
\text { expansion, an unexpected } \\
\text { conclusion is created and } \\
\text { reached from scratch }\end{array}$ & $\begin{array}{l}\text { When escaping the palace with } \\
\text { 'Anna' they roll on the snow literally } \\
\text { being a 'snow ball' by intentionally, } \\
\text { or as planned, it will never be known } \\
\text { but as they keep on rolling on the } \\
\text { snow, we question what would } \\
\text { happen and eventually with the body } \\
\text { separating and combining they do } \\
\text { escape dramatically. }\end{array}$ \\
\hline Word/speech & $\begin{array}{l}\text { The repetition of words will } \\
\text { only make us laugh when the } \\
\text { mental element is represented } \\
\text { by a special pleasure and itself } \\
\text { represents a material pleasure. }\end{array}$ & $\begin{array}{l}\text { To different questions he repeatedly } \\
\text { answers with "Yes, Why?" and this } \\
\text { is an example of 'Jack in the box' } \\
\text { where laughter is induced by } \\
\text { repetition. }\end{array}$ \\
\hline Personality & $\begin{array}{l}\text { A person's flaw gives us } \\
\text { laughter. } \\
\text { We do not only laugh at other } \\
\text { people's flaws but also at their } \\
\text { merits. }\end{array}$ & $\begin{array}{l}\text { He bluffed many times that he had } \\
\text { helped 'Anna' and ensured that he } \\
\text { will help her to escape. These were } \\
\text { able to give the audience laughter as } \\
\text { stated by Bergson that it was not due } \\
\text { to immorality but due to the } \\
\text { antisocial aspects of him. Therefore } \\
\text { the small flaws and humiliations had } \\
\text { been a source in giving laughter. }\end{array}$ \\
\hline
\end{tabular}

Bergson has stated that comedy is one of the pleasures of imitating life.

Bergson has stated that the reason we laugh is not because of rational but when it is emphasized more on instinct or physically capability. This is when the human-like factor is interlocked with mechanical factors and this is reflected to us. By Bergson's theory, when the snowman, Olaf, talks and acts like a human, it itself is a main factor to laughter.

In Bergson's theory of laughter by shape/form and movement, much of the theory had been compared to animation. This is because animation had been reflected as effective media to 
give laughter. In Bergson's type of laughter theory, distorted but humorous design and unbalanced body corresponds to the shape/form factor and with the extensive exaggeration, the body frequently separates and moves on its own and combines to be one. This corresponds to the laughter by movement but also the laughter by situation where the repetition of 'Jack in the box', reversal of 'Dancing Jack' and the duplication and crossing of 'Snow ball' are embraced. Pleasure by repetition of words can be seen when Olaf repeatedly answers to questions as "Yes, Why?" or when he repeatedly say he will rescue and save them but doesn't, and giving up easily to situations give us a thing to smile about. His optimistic bluffing is not unethical, therefore we are able to laugh to his flaws and this represents the Bergson's 'laughter by personality' theory.

This is a newly created character and it can be seen that its personality and design has been made within the type of laughter and the factors in causing laughter.

By analyzing the laughter factor of each media based on their nature and organizing a category chart to include the categories reflecting the current society is being planned and this will be used in the future in character creation and design. Further research will be conducted to supplement this cause.

\section{References}

[1]. "Samsung Fashion Institute: Fashion \& Entertainment", www.samsungdesion.net.

[2]. "Sinsanghun, Humor wins, Samanpakers, (2010), pp. 75-76.

[3]. L. Yunseok, Science of laughter, Sciencebooks, (2011).

[4]. R. Park, Korean Society of Basic Design \& Art, vol. 7, no. 4, (2006), www.thenumbers.com/movies/records/100million.php.

[5]. H. Bergson, "Le Rire: Essaisur la significance du comique", (1899).

[6]. L. Huiyeong and D. S. M. Hwasa, (2012), pp. 13-116.

[7]. H. Bergson, (Le) rire, essaisur la signification du comique, (1992), Jeongyeonbok, Segaesa.

[8]. P. Gyeongsuk and J. Gyeongran "Sourceof enjoyment factors in PoKetMonseutes", Korea communication association newspaper, vol. 44, no. 3, pp. 153-189.

[9]. M. La France, Lip Service, (2011), Psychology of laughter, Jungangbooks, (2012).

[10].P. Yeongwon, Design Humor, Angraphics, (2013).

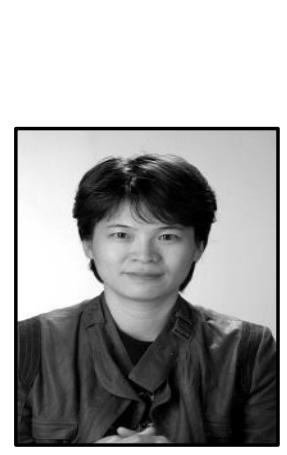

\section{Authors}

Eunkoung Lee, She studied in the Graduate School of Fine Arts Education at Kyung Hee University majoring in Western Painting in Seoul, Republic of Korea and finished the Alias|Wavefront course at University of Toronto in Canada. She received Master of Fine Arts degree in Animation from Hongik University in 2006. She had been running an educational institution for Post Production and 3D Animation for 10 years.

Ms Lee is currently teaching New Media Art at Dong-eui University in Busan and she is undertaking the doctoral course at Kyung Hee University.

She has been involved in group exhibitions four times and is interested in 3D Animation and Media Art. . 


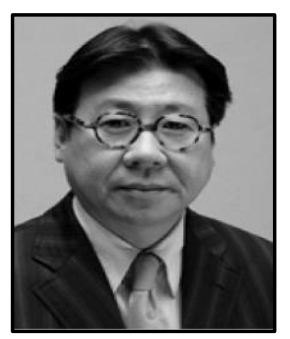

Myoungsik Choi, He received Master of Fine Arts degree in industrial design at Royal College of Art and Design. Currently, he is a professor at Kyung Hee University in industrial design and holds many different positions such as the dean of the College of Art and Design at Kyung Hee University, the director of the Graduate School of Art Fusion Design at Kyung Hee University and Chief of Research Lab of Art and Design.

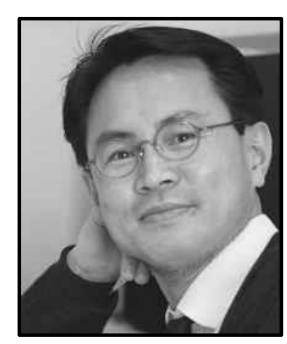

Kim Cheeyong, He received the B.S. degree, M.S. degree and $\mathrm{Ph} . \mathrm{D}$. degree from Inje University, Republic of Korea in 1991, 1994 and 2000 respectively. He is visiting professor at Oxford University in 2007, and visiting professor of the Digital Clothing Center at Seoul National University in 2012. Currently, he is a professor of Department of Visual Information Engineering at Dong-eui University. Prof. Kim held private exhibitions four times both in Seoul and China and joined over 2010 international group exhibitions. With his deep interest in 3D Animation, Fractal \& Chaos Design, Computational Simulation, and $3 \mathrm{D}$ virtual fashion fitting system. 